\title{
REVIEW \\ Medical rehabilitation of spinal cord injury following earthquakes in rehabilitation resource-scarce settings: implications for disaster research
}

\author{
JE Gosney ${ }^{1,2}$, JD Reinhardt ${ }^{1,3,4}$, PM von Groote ${ }^{3,4}$, FA Rathore ${ }^{1,2,5,6}$ and JL Melvin ${ }^{7}$
}

Study design: Narrative literature review.

Objectives: To (1) summarize epidemiological and scientific research on spinal cord injury (SCI) populations from three severe earthquakes (EQs) in rehabilitation resource-scarce settings; (2) summarize SCI rehabilitation services by local and foreign providers in response to these EQs and (3) provide implications including research gaps for a supporting global scientific research agenda.

Setting: International.

Methods: A literature review was conducted using PubMed to identify epidemiological studies reporting data on SCl survivors of the 2005 Kashmir EQ in Pakistan, the Sichuan EQ of 2008 in China and the 2010 Haiti EQ. A follow-up review on the SCI rehabilitation services provided by local and foreign providers in response to these EQs was also performed.

Results: Review of the scientific literature revealed the qualitative trends in focused EQ victim epidemiological data, including SCI classification and types of medical complications. Selected EQ country narratives showed that post-disaster $\mathrm{SCl}$ rehabilitation services were expanded by adapting local resources with international assistance to manage the significant numbers of $\mathrm{SCl}$ survivors. The resulting $\mathrm{SCl}$ research was limited.

Conclusion: A global disaster research agenda for $\mathrm{SCl}$ in EQs in rehabilitation resource-scarce settings is needed to strengthen the evidence base for improvement of clinical management and outcomes for SCI EQ survivors. Expansion of this limited narrative review into a systematic review to identify additional research gaps is a proposed next step. Effective disaster setting data management and research collaborations of foreign and local $\mathrm{SCl}$ disability and rehabilitation stakeholders will be required for agenda implementation. Spinal Cord (2013) 51, 603-609; doi:10.1038/sc.2013.50; published online 11 June 2013

Keywords: disaster research; earthquake; spinal cord injury; medical rehabilitation; epidemiology

\section{INTRODUCTION}

Natural disasters can be defined as 'a situation (incident) or event which overwhelms local capacity, necessitating a request to a national or international level for external assistance.. ${ }^{1}$ Large-scale natural disasters often result in immediate, significant loss of life as well as severe disabling injuries, including fracture, amputation, traumatic brain injury and spinal cord injury (SCI), which can result in longterm physical impairment. Natural disasters most commonly occur in low-resource settings where disaster response plans usually do not include strategies for physical rehabilitation. ${ }^{2}$

Earthquakes (EQs) are natural disasters that occur when the earth's tectonic plates slip past one another, releasing waves of energy into the surrounding ground. Collapse of masonry buildings is by far the most common cause of injury and death in EQs. Quakes centered in urban areas often destroy significant material and human public health infrastructure; communication and transportation networks as well as medical facilities are destroyed, and healthcare workers and their families are displaced, injured and killed. Individual risk factors include pre-existing disabilities, extremes of age, chronic illness and lack of mobility. Entrapment, the occupant's location within a building and time-to-rescue are prognostic indicators. ${ }^{3}$ The mass casualty response to EQs comprises the four essential elements of disaster medical response: (1) search and rescue; (2) triage and initial stabilization; (3) definitive medical care; and (4) evacuation. ${ }^{4}$ Regarding suspected spinal injury, on-scene spinal immobilization, intravenous access and maintenance of cervical alignment (if appropriate) are critical to a positive outcome, and rapid referral to a multidisciplinary care facility with appropriate rehabilitation services is indicated. ${ }^{5}$

This narrative review summarizes epidemiological scientific research on SCI populations from three severe EQs in rehabilitation resource-scarce settings. The 2005 'Kashmir earthquake' in Pakistan, the 'Sichuan earthquake' of 2008 in China and the '2010 Haiti earthquake' are included. The background context of the local and foreign emergency medical rehabilitation response to these EQs is provided. EQs were selected as the disaster type because of their catastrophic potential and as the primary mechanism of injury, collapsing structures, is a direct cause of SCI. These specific EQs

\footnotetext{
${ }^{1}$ Rehabilitation Disaster Relief Committee, International Society of Physical and Rehabilitation Medicine (ISPRM), Geneva, Switzerland; ${ }^{2}$ International Rehabilitation Forum (IRF), Ann Arbor, MI, USA; ${ }^{3}$ Swiss Paraplegic Research, Nottwil, Switzerland; ${ }^{4}$ Department of Health Sciences and Health Policy, University of Lucerne, Lucerne, Switzerland; ${ }^{5}$ Department of Rehabilitation Medicine, Combined Military Hospital, Lahore Cantt, Pakistan; ${ }^{6}$ Michael Mole Fellowship, World Association of Disaster and Emergency Medicine (WADEM), Madison, WI, USA and ${ }^{7}$ Department of Rehabilitation Medicine, Jefferson Medical College of Thomas Jefferson University, Philadelphia, PA, USA Correspondence: Dr JE Gosney, Rehabilitation Disaster Relief Committee, International Society of Physical and Rehabilitation Medicine (ISPRM), Rue de Chantepoulet 1-3, PO Box 1726, CH-1211, Geneva 1, Switzerland.

E-mail: gosneyjr@hotmail.com
}

Received 9 October 2012; revised 12 March 2013; accepted 27 April 2013; published online 11 June 2013 
were selected as each had a significant impact on the affected population and public health infrastructure of the respective country setting; having occurred recently, their research record reflects the deficient state of global disaster-related SCI research in rehabilitation resource-scarce settings, and the authors had first-hand experience with these EQs.

This paper specifically aims to:

- summarize selected EQ characteristics and EQ SCI epidemiological data from the scientific literature;

- summarize local and foreign medical rehabilitation service delivery to SCI victims in three recent severe EQs in rehabilitation resourcescarce settings;

- summarize the general state of SCI disaster rehabilitation research in low-resource settings based on available scientific literature from the focus EQs;

- discuss the implications for development of a global scientific research agenda for SCI in EQs in low-resource settings.

\section{MATERIALS AND METHODS}

An initial literature review was conducted using PubMed to identify scientific studies reporting epidemiological data on SCI victims of the 2005 Kashmir EQ in Pakistan, the Sichuan EQ of 2008 in China and the 2010 Haiti EQ. Using the keyword strategy 'epidemiology AND spinal AND earthquake', 26 papers were retrieved, of which 16 addressed the selected EQs. Seven of these papers were excluded either due to lack of epidemiological data on $\mathrm{SCI}^{6,7}$ or because they cited earlier publications. ${ }^{8-12}$ The remaining eight studies ${ }^{13-20}$ were analyzed. Three additional papers on SCI following the EQs in China and Haiti21-23 written by the authors (JR, JG) and another paper by Burns ${ }^{24}$ were identified by manual search. Data from these papers were extracted on study parameters, population demographics, SCI characteristics (level of lesion and neurological deficit), medical complications and deaths due to complications. Individual EQ characteristics were also extracted, including seismic activity date and time, seismic magnitude and epicenter location. Respective EQ estimates of the number of injured and dead were retrieved from the Emergency Events Database, ${ }^{25}$ from which injury-to-death ratios and the SCI percentage of total injuries were calculated.

A follow-up literature search for general and SCI-specific rehabilitation services provided by local and foreign providers in these EQs was also performed. A combination of the terms 'medical/SCI rehabilitation and Kashmir/Sichuan/Haiti earthquake' was used to search PubMed. Acute and longer-term SCI rehabilitation responses, as well as the general emergency medical rehabilitation response country setting contexts, were investigated.

\section{RESULTS}

Selected data from recent severe EQs

Table 1 shows selected data from the 2005 Kashmir EQ in Pakistan, the 2008 Sichuan EQ in China and the 2010 Haiti EQ. Haiti and Pakistan are classified by Richter scale magnitude as major (7.0-7.9) EQs and Sichuan as a great EQ (8.0-8.9). All EQs occurred during daytime, working hours, and the epicenter was near a large, densely populated urban area in Pakistan and Haiti. The injury-to-death ratio was highest in China and lowest in Haiti. EQs resulted in many new SCI survivors, with the highest incidence in Pakistan and the lowest in Haiti.

\section{SCI studies on selected EQs from the scientific literature}

Table 2 summarizes epidemiological data on SCI populations from studies on selected EQs of interest in the scientific literature. Most studies provide mid-level evidence. Study parameters, population demographics, SCI characteristics (level of lesion and neurological deficit), medical complications and deaths due to complications are presented. Some studies ${ }^{13,14,17,18}$ were not SCI-specific and therefore do not provide information on this population. Even some SCIspecific studies ${ }^{15,24}$ provide only limited data on SCI characteristics and complications. Only one study, a prospective cohort investigation by $\mathrm{Li}$ from China, provides rigorous scientific evidence on rehabilitation effectiveness. ${ }^{22}$

Available data across EQs reveal several patterns of injury: (1) more females than males were injured; (2) thoracic and thoracolumbar injuries were most common in surviving victims; (3) few cervical injuries and complete tetraplegia cases were observed; (4) pressure sores and urinary tract infections were common complications; and (5) deep venous thromboses were reported infrequently and appear to be associated with the deaths attributed to pulmonary embolism.

\section{EQ SCI rehabilitation country setting narratives}

Pakistan, 2005 Kashmir EQ. The 2005 Kashmir EQ resulted in an estimated 76000 deaths and 106000 injured, many with long-term disabling conditions. Most casualties occurred in Muzaffarabad, the capital city of Pakistan-administered Kashmir, where minimal pre-EQ health-care infrastructure existed and the main hospital was destroyed; effectively no institutional rehabilitation services were available.

The Pakistani military coordinated an effective, large-scale medical airlift of severely injured victims. However, as many first responders were not skilled in emergent SCI management, several incomplete SCI cases were exacerbated during the evacuation. ${ }^{8}$ Most SCI victims were flown to the Armed Forces Institute of Rehabilitation Medicine (AFIRM) in Islamabad-Rawalpindi, which operated the country's only spinal rehabilitation unit. Although bed capacity was expanded, many of the estimated 700 new SCI patients could not be accommodated, requiring establishment of nearby makeshift spinal injury centers. ${ }^{20}$

Additional military physiatrists were transferred to AFIRM, where they led multidisciplinary rehabilitation teams in managing the significant numbers of traumatic, disabling injuries, including SCI victims. They also consulted at the makeshift centers and supported patient management by providing direct patient care, educating staff on SCI management, conducting patient and caregiver education, and collecting data. Because of the limited availability of physiatrists, the makeshift SCI centers were primarily staffed by physicians from other specialties, ${ }^{9,26}$ allied rehabilitation professionals (physical/occupational therapists) and social workers. Although these physicians stabilized and saved lives acutely, their relative lack of rehabilitation expertise resulted in inaccurate assessments and high rates of complications. ${ }^{26}$ AFIRM patients under direct physiatrist care reported better quality of life than patients in the makeshift centers. ${ }^{9}$ Community-based rehabilitation initiatives in post-EQ Pakistan were limited, sometimes resulting in medically dischargeable patients remaining in hospitals because of lack of care alternatives in the community. ${ }^{11}$

The international humanitarian medical rehabilitation response to the 2005 Kashmir EQ mainly consisted of rehabilitative post-surgical care provided by foreign medical teams. Teams from the Swiss Paraplegic Centre and Handicap International, an international rehabilitation services non-governmental organization (NGO), provided SCIspecific services as well at AFIRM and the National Institute of Rehabilitation Medicine SCI Center. Also, teams from Canada, Cuba and South Africa comprised of physical therapists, occupational therapists, prosthetic and orthotic technologists, and clinical psychologists provided SCI clinical services, conducted prosthetic and orthotic training, and donated therapy equipment. No foreign physiatrists responded as members of organized teams; however, 
Table 1 Selected data from recent severe earthquakes

\begin{tabular}{lll}
\hline & Pakistan/Kashmir & China/Sichuan \\
\hline Date & 8 October 2005 & 12 May 2008 \\
Time of occurrence $(24 \mathrm{~h})$ & $08: 52$ & $14: 48$ \\
Epicenter & Muzaffarabad & Wenchuan county \\
Magnitude (Richter scale) & 7.6 & 8 \\
Description & Major & Great \\
No. of injured & 128309 & 368412 \\
No. of deaths & 73338 & 87564 \\
Injury-to-death ratio & 1.75 & 4.21 \\
No. of surviving SCl victims & 741 (Mallik 2010) & 336 (author estimate \\
Percentage SCl of injured & 0.00575 & 300000 \\
\hline
\end{tabular}

Abbreviations: $\mathrm{EQ}$, earthquake; $\mathrm{SCl}$, spinal cord injury.

aEstimate is derived from 14000 injured victims hospitalized, ${ }^{25} 2.4 \%$ with $\mathrm{SCl}^{21}[(14000 \times 0.024)=336]$.

several expatriate Pakistani physiatrists, as well as others from the UK and US, responded independently.

China, 2008 Sichuan EQ. The 2008 Sichuan EQ resulted in an estimated 88000 deaths and 368000 injured persons; almost 100000 of the injured were hospitalized and more than half of the health facilities in the most affected areas were damaged or destroyed. The quake epicenter was 50 miles northwest of Chengdu, the capital of Sichuan province, in a rural, mountainous terrain, which that complicated rescue, transport and referral. A military-led local response was activated immediately, resulting in rapid, efficient onward transfer of critically injured victims to hospitals in about 60 cities across 20 provinces. $^{27}$

After being stabilized (and definitive spinal surgery performed if indicated) in the distant provincial hospitals, many without rehabilitation services, the majority of SCI victims were discharged after several months back to their homes in Chengdu province, whereas some were transferred to three Sichuan tertiary care hospitals (West China Hospital, Jiangyou Orthopedic Hospital and Mianzhu County Hospital) that had established rehabilitation departments to manage patients with severe, disabling traumatic injuries including SCI. SCI transfers suffered from a relatively high incidence of medical complications because of the lack of preventive rehabilitation measures and formal rehabilitation programming practiced at the transferring hospitals and also because of the lengthy transfer between facilities in sometimes compromising conditions. Multidisciplinary rehabilitation teams led by physiatrists from extra-provincial hospitals provided comprehensive management of SCI patients. Qualified patients (that is, those who could tolerate physical therapy) participated in individualized physical rehabilitation programs, which demonstrated significantly improved functional rehabilitation outcomes including ambulation ability, wheelchair mobility and activities of daily living independence. ${ }^{21}$

Post-earthquake SCI services were mainly administered via the 'NHV model', a collaborative rehabilitation services program established by the Chinese government and the Chinese Association of Rehabilitation Medicine, which employed international NGOs (N), local health departments $(\mathrm{H})$ and rehabilitation 'volunteers' $(\mathrm{V})$. The NHV model also provided community-based rehabilitation and included a rehabilitation training and qualification program for local professionals, as well as tools for patient management and education. ${ }^{28}$

Foreign medical teams (for example, Taiwan, Russia, Hong Kong, Japan, Italy, Germany, France, UK, USA and Cuba) spent 3 weeks in Sichuan, treating 24410 cases at 11 sites, which included surgical and nursing care ${ }^{29}$ as well as rehabilitative post-surgical care. Training of host medical services was also provided. Notably, the UK team implemented a joint Sino-Anglo program for ongoing cooperation in emergency medicine, disaster planning/preparedness and management of SCI. ${ }^{6}$ Foreign medical rehabilitation services were primarily provided by Handicap International (which had a pre-EQ presence) and the Hong Kong Children's Foundation via the NHV model.

Haiti, 2010 EQ. The 12 January2010 Haiti EQ resulted in an estimated 223000 deaths and 300000 injured. Among them were about 150 SCI victims, most of whom survived collapsed buildings in densely populated Port-au-Prince. Many others died presumably because of lengthy response, extraction and referral times caused by the chaotic conditions; medical infrastructure was effectively destroyed. Before the EQ, few individuals survived a severe SCI in Haiti $^{30}$ and specialized care was essentially unavailable.

Many responding foreign organizations provided acute SCI care and within a week began referring to identified SCI sites, including Project Medishare in Port-au-Prince, Haiti Hospital Appeal in Cap Haitien (northern Haiti) and St Boniface Hospital in Fond-des-Blancs (southern Haiti). At least 25-30 injured victims were evacuated to North American and Caribbean medical centers for management of their complex medical and rehabilitation needs. ${ }^{30}$ Others were flown to the US Navy hospital ship Comfort in Port-au-Prince harbor and were either stabilized or operated on, and subsequently discharged for ongoing care to SCI sites in Haiti or in the United States. ${ }^{31}$ Rehabilitation resources were coordinated directly between the providing organizations and more centrally by the United Nations/ World Health Organization/Pan American Health Organization Health Cluster's 'Injury Rehabilitation and Disability' Workgroup, the 'disability subcluster. ${ }^{32}$ A coalition of NGOs comprises the Haiti SCI Group, which currently functions as the central coordinator for SCI care in Haiti. Besides helping to manage bed availability and patient referral, the group mediates issues of mutual concern and supports advocacy, training and research initiatives. ${ }^{30}$

\section{DISCUSSION}

\section{Summary of EQ SCI rehabilitation country narratives}

Although the underdeveloped, pre-EQ rehabilitation infrastructures were severely disrupted in the Pakistan, China and Haiti quakes, rehabilitation services were quickly expanded by adapting local resources supplemented by foreign support to manage the significant burden of disabling injuries, including SCI. Most SCI survivors were effectively evacuated to definitive care; military-led disaster zone evacuations in Pakistan and China were notably successful, as was the 


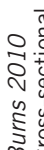

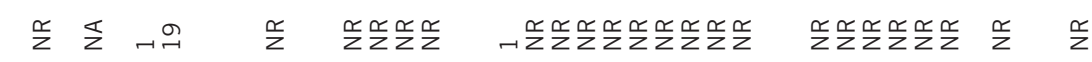

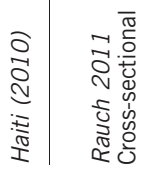

ब.

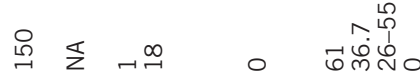

$\rightarrow 6 \infty 0 ت ี 6 テ 60$

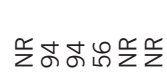

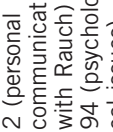

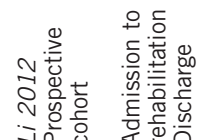

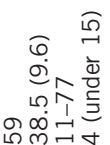

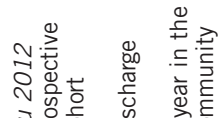

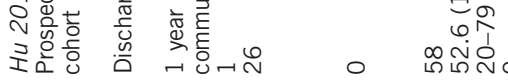

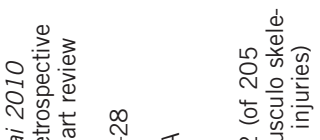

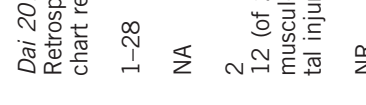

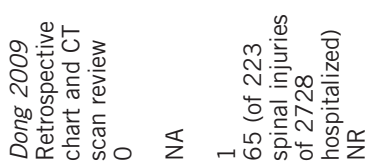

孚爱品

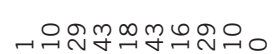

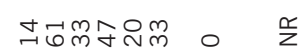

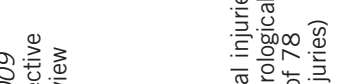

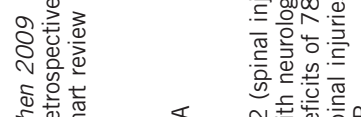

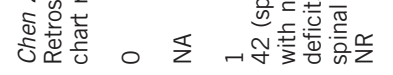

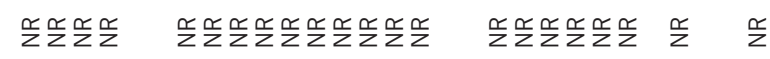

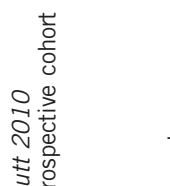<smiles>[CH]=C</smiles>

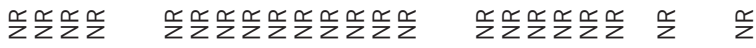

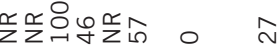

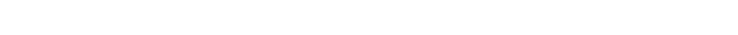

$$
\text { 作 }
$$

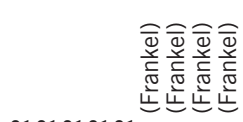

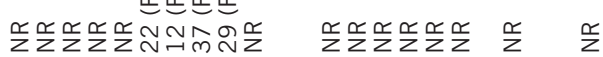

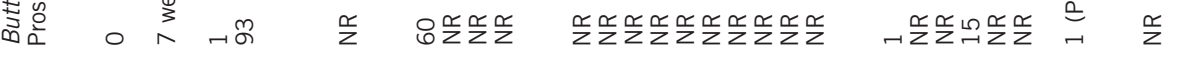

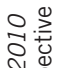

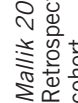

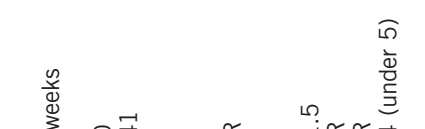

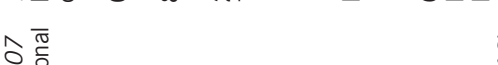

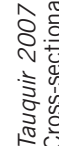

ก

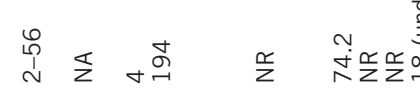

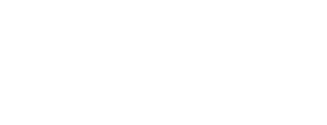

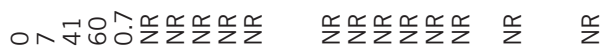

离

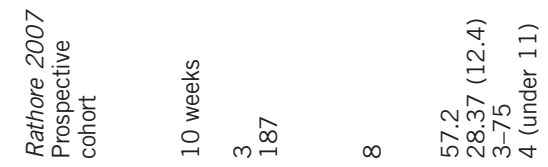

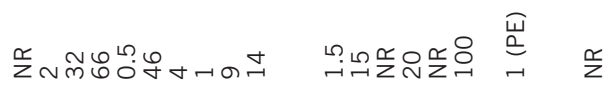

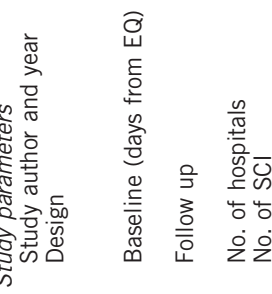

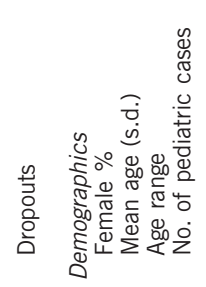

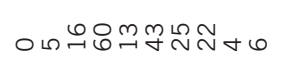
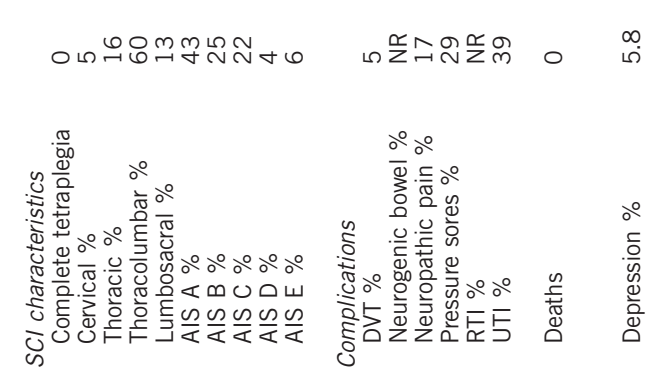
US military airlift to US (including Comfort) and Haitian facilities in Haiti. Acute and longer-term SCI management was generally adequate, with more complications reported in Pakistani and Chinese institutions.

Foreign SCI expertise in the form of foreign medical teams, NGOs, academic and research institutions, and individual providers was an integral component of the emergency SCI EQ responses in Pakistan and Haiti and across the continuum of rehabilitation response in all three EQs. Besides providing direct clinical care and programmatic support (that is, community-based rehabilitation), foreigners coordinated with a range of local stakeholders-government ministries, disaster management agencies, higher-education institutions, disabled persons organizations, local providers, and others - to increase SCI rehabilitation service capacity in other ways as well. Particularly, rehabilitation and general health professionals as well as community health workers were trained to provide appropriate SCI care across a range of post-EQ settings. Foreign stakeholders also sponsored academic exchange programs, financed rehabilitation facilities and collaborated on scientific research projects.

\section{Summary of EQ SCI epidemiological data}

Epidemiological data trends from the focus EQs suggest that females are at higher risk for SCI than males; conversely, incidence is higher in men in non-EQ, SCI populations. ${ }^{33}$ EQ occurrence in traditional societies during daytime, working hours, when women are likely to be at home performing domestic duties, can plausibly account for this finding. Cervical SCI cases are relatively infrequent in the populations studied, as most presumably died from medical complications before hospital arrival; lengthy times for rescue, extrication from rubble and transfer to definitive care contributed. This pattern manifested across Chinese centers treating Sichuan SCI survivors. $^{22}$ Preventable complications including pressure sores and urinary tract infections were common findings in this review series; lack of preventive measures practiced in study institutions due to the absence of rehabilitative care protocols may be causative. Although rarely reported, deep venous thrombosis appears to be associated with mortality. A subpopulation with clinical depression is noted in the community setting. ${ }^{22}$ Rehabilitation effectiveness was demonstrated by significantly improved functional rehabilitation outcome measures, including activities of daily living, ambulation ability and wheelchair mobility assessed at the beginning and end of an individualized, institutional rehabilitation program. ${ }^{22}$ Medical complications were significantly reduced during the rehabilitation program because of appropriate clinical management.

\section{State of research on SCI rehabilitation following EQs}

This review identified relatively few, high-quality EQ SCI studies, indicating the need for additional robust scientific evidence upon which to base SCI rehabilitation interventions and evaluate outcomes following EQs in low-resource settings. This paucity of SCI-specific literature reflects the broader disaster evidence base. Although a recent comprehensive review of disaster-specific literature revealed 'medical health' as the leading primary research topic following natural disasters $(38 \%),{ }^{34}$ a related investigation found that 'health-care provision' and 'specific diseases' comprised only $10.2 \%$ of the topics in developing-world disaster publications. Moreover, $<1 \%$ of articles retrieved addressed disasters in the developing world, where, in fact, $85 \%$ of disasters occur. ${ }^{35}$ Literature on medical rehabilitation in disaster, including SCI, is even scarcer.

Besides the low number of scientific publications, a low level of evidence characterizes the disaster medicine literature as well. Level IV and V publications (based on a standardized classification of levels of evidence formulated by the Centre for Evidence-based Medicine ${ }^{36}$ ) consisting mostly of internal documents published by international relief agencies predominate. Historically the main data source for health relief workers, this gray literature contributes little to the evidence base. Generation of level II/III cohort studies and outcomes research as well as level I systematic surveys with appropriate sampling and other sound epidemiological methods are necessary. ${ }^{38}$ Level I randomized controlled trials are not feasible in the disaster setting. Regardless of the level of evidence of the study performed, however, conduct of operational and clinical research projects is particularly difficult in disasters and other humanitarian crises, given the numerous methodological, technical and logistical challenges including study design, collaboration with international and national authorities, and mobilization of local, national and international staff. 37,38

The preceding EQ SCI rehabilitation country narratives describe the medical rehabilitation infrastructure and service delivery context in which SCI research was performed in these settings. Research following the Kashmir EQ was limited, as specific disabling injuries including SCI were not delineated in epidemiological injury data collected during the emergency phase by the Government of Pakistan's National Database Registration Authority. ${ }^{9}$ Further, data collection and scientific studies performed by health institutions and rehabilitation professionals were generally not supported by the Pakistani government although qualitative investigation was performed by physicians at AFIRM and the makeshift SCI centers. Letters to the editor, commentaries and other expert opinion reports comprise most of the available Kashmir EQ literature.

China has generated comparatively more, high-quality EQ SCI rehabilitation research (including rehabilitation effectiveness) than Pakistan or Haiti due primarily to its well-organized rehabilitation response. The comprehensive NHV rehabilitation services model subsumed victim data collection, database development and program evaluation, thereby facilitating scientific research by collaborating NGOs, medical and academic institutions, rehabilitation professional societies and local authorities. Many academic medical institutions have published independently as well, reflecting China's capacity for high-quality scientific research. ${ }^{39}$ China's growing SCI rehabilitation evidence base from the Sichuan EQ is informing evolving medical rehabilitation practice and preparedness efforts for its next severe EQ.

The relative lack of local institutional research and medical rehabilitation infrastructure in Haiti has limited SCI research performed by local and foreign stakeholders since the 2010 EQ. Active in Haiti before the EQ, Handicap International was positioned to conduct a preliminary injury report within 2 weeks; hospital survey estimates of disabling injuries, including SCI, and patient management as well as resource allocation recommendations were provided. ${ }^{40}$ Handicap International also utilized a corresponding rapid assessment tool to identify the emergent needs of SCI victims. ${ }^{30}$ At Haiti Hospital Appeal, Swiss Paraplegic Research piloted a newly developed tool based on the ICF, which assessed the level of functioning as well as corresponding rehabilitation need and required rehabilitation expertise. ${ }^{23}$ Healing Hands for Haiti has developed a SCI database including EQ survivors, which is being used for research to benefit the Haiti SCI Group. Healing Hands is also conducting a study with Dalhousie University on perceptions of persons in Haiti living with disability. In sum, the body of SCI research from the Pakistan, China and Haiti EQs, though limited, represents the range of challenges and solutions in conducting SCI EQ disaster rehabilitation research in low-resource settings. 


\section{Research implications}

The SCI rehabilitation research summarized in this limited, narrative review forms the basis for a global scientific research agenda for SCI in EQs in low-resource settings. Epidemiological patterns raise direct follow-on research questions. The higher prevalence of thoracic and thoracolumbar than cervical SCI, for example, suggests that mortality studies are needed to clarify the cause and timing of death with follow-on evaluation of response, rescue, extrication and transfer mechanisms. Clinical complications and mental health sequelae require further investigation as well. Medical complications could be addressed by altering existing standards such as the Paralyzed Veterans of America Consortium for Spinal Cord Medicine clinical practice and consumer guidelines for early acute management of SCI; bladder, neurogenic bowel and respiratory management; prevention of thromboembolism and pressure ulcers; and depression (see Table 2). ${ }^{41}$ Adapting current SCI best practices for use in EQs in low-resource settings would exemplify 'crossing the quality chasm. ${ }^{42}$

Expansion of this review into a systematic review with additional EQs and broader inclusion criterion to specify research gaps and corresponding questions is a proposed next step for developing a comprehensive SCI EQ research agenda. Resulting papers, guidelines and other research would address SCI rehabilitation across the disaster continuum of response, including pre-EQ planning and post-EQ field, institutional and community-based service delivery. Functional recovery of SCI victims would be emphasized. A previous World Health Organization/Europe consultation on guidelines for physical rehabilitation of wounded in disasters that includes SCI is a general reference. ${ }^{43}$

Robust scientific research depends on accurate, systematic collection, reporting and analysis of disaster data. Although international data standards for SCI in EQ (or for disabling injuries in disasters generally) do not exist, standards including the International Standards for Neurological Classification of Spinal Cord Injury, International SCI Core Data Set, the ICF Core Sets for SCI, and the International SCI Pain Classification ${ }^{44-49}$ are available for developing EQ data management form templates. Templates could be used to manage SCI EQ rehabilitation data to support resource allocation, victim management and outcome monitoring, and scientific research over the disaster response continuum. For maximum effectiveness, SCI EQ data collection and reporting should integrate with the corresponding World Health Organization Inter-Agency Standing Committee, Global Health Cluster humanitarian response mechanism, and therefore be developed in view of the proposed International Standard Reporting Template for Surgical Care and paired patient Surgical Record Template (which include medical rehabilitation referral). Integrated development would also help to prioritize data collection and reporting in the chaotic disaster setting, mitigating competing priorities. ${ }^{50}$ Integration of SCI EQ data management into the overall global humanitarian response mechanism would also facilitate organizational sharing of medical rehabilitation (including SCI) data, and therefore pooled quantitative research, resulting in higher-level evidence.

\section{Methodological limitations}

This narrative review was methodologically limited by its confinement to the medical literature. Although PubMed was searched exclusively as it is globally known and available, including EMBASE would have increased the yield of scientific articles, ${ }^{33}$ as would searching scientific databases unique to the focus EQ settings. The Center for International Rehabilitation Research Information and Exchange (CIRRIE) Database of International Rehabilitation Research is another globally accessible relevant clinical database. ${ }^{51}$ The Cochrane Review Evidence Aid 'Resources for Earthquakes' special collection includes reviews on acute management of SCI, ${ }^{52}$ and Cochrane's collection of databases, journals and websites for low and middle-income countries also contains relevant reference material. ${ }^{53}$ Besides the peer-reviewed medical literature and other potentially relevant clinical databases and special collections, the gray literature produced by international medical relief organizations was not systematically searched either. ReliefWeb, a service of the United Nations Office for the Coordination of Humanitarian Affairs, archives disaster reports from various humanitarian aid agencies among other online repositories. ${ }^{54}$ Also, the literature search of the EQ country narratives would have benefitted from a more specific search strategy.

Practically, this review was limited to qualitative analysis of studies from the literature because of their scarcity and heterogeneity of reporting; meta-analysis was not possible. Such was also the case in a recent systematic review of a foreign medical team's surgical caseload data. ${ }^{55}$ Hence, although broadening the country context for interpreting SCI EQ service delivery to include the legal, political and cultural pre-EQ status of disability and medical rehabilitation would have strengthened this review, interpretation of the available literature would not necessarily have been simplified. Given the significant variability of EQ setting contexts and of the local and foreign SCI rehabilitation responses, three EQs were considered sufficient to demonstrate general salient trends for indicating the significant need for stronger scientific research.

\section{CONCLUSION}

A global disaster research agenda for SCI in EQs in rehabilitation resource-scarce settings is needed to strengthen the evidence base for improvement of clinical management and outcomes for SCI EQ survivors. Expansion of this limited narrative review into a systematic review to specify additional research gaps is a proposed next step. Effective disaster setting data management and research collaborations of foreign and local SCI disability and rehabilitation stakeholders will be required for agenda implementation.

\section{CONFLICT OF INTEREST}

The authors declare no conflict of interest.

\section{ACKNOWLEDGEMENTS}

We thank Drs Xia Zhang (Chinese Association of Rehabilitation Medicine; ISPRM Committee on Rehabilitation Disaster Relief) and Colleen O'Connell (Healing Hands for Haiti; ISPRM Committee on Rehabilitation Disaster Relief; ISCoS Disaster Committee) for their review of the China and Haiti SCI rehabilitation narratives, respectively. Gratitude is also extended to Dr Andrew Haig (International Rehabilitation Forum; ISPRM Committee on Rehabilitation Disaster Relief) for his concept guidance and to Dr Joel DeLisa (ISPRM Committee on Rehabilitation Disaster Relief) for his review of the manuscript.

1 Burkle FM, Greenough PG. Impact of public health emergencies on modern disaster taxonomy, planning, and response. Prehosp Disaster Med 2008; 2: 192-199.

2 Reinhardt JD, Li J, Gosney J, Rathore FA, Haig AJ, Marx M et al. International Society of Physical and Rehabilitation Medicine's Sub-Committee on rehabilitation disaster relief. Disability and health-related rehabilitation in international disaster relief. Glob Health Action 2011: 4: 1.

3 Macintyre AG, Barbera JA, Smith ER. Surviving collapsed structure entrapment after earthquakes: a 'time-to-rescue' analysis. Prehosp Disaster Med 2006; 21: 4-17.

4 Briggs SM. Earthquakes. Surg Clin North Am 2006; 86: 537-544.

5 Gautschi OP, Cadosch D, Rajan G, Zellweger R. Earthquakes and trauma: review of triage and injury-specific, immediate care. Prehosp Disaster Med 2008; 23: 195-201. 
6 Redmond AD, Li J. The UK medical response to the Sichuan earthquake. Emerg Med J 2011; 28: 516-520.

7 lezzoni LI, Ronan LJ. Disability legacy of the Haitian earthquake. Ann Intern Med 2010; 152: 812-814.

8 Rathore MF, Butt AW, Aasi MH, Farooq F. Re: complications in patients with spinal cord injuries sustained in an earthquake in northern Pakistan. J Spinal Cord Med 2008a; 31: 118.

9 Rathore FA, Farooq F, Muzammil S, New PW, Ahmad N, Haig AJ. Spinal cord injury management and rehabilitation: highlights and shortcomings from the 2005 earthquake in Pakistan. Arch Phys Med Rehabil 2008b; 89: 579-585.

10 Rathore MF, Hanif S, New PW, Butt AW, Aasi MH, Khan SU. The prevalence of deep vein thrombosis in a cohort of patients with spinal cord injury following the Pakistan earthquake of October 2005. Spinal Cord 2008c; 46: 523-526.

11 Rathore MF, Faroog F, Butt AW, Gill ZA. An update on spinal cord injuries in October 2005 earthquake in Pakistan. Spinal Cord 2008d; 46: 461-462.

12 Priebe MM. Spinal cord injuries as a result of earthquakes: lessons from Iran and Pakistan. J Spinal Cord Med 2007; 30: 367-368.

13 Dai ZY, Li Y, Lu MP, Chen L, Jiang DM. Clinical profile of musculoskeletal injuries associated with the 2008 Wenchuan earthquake in China. Ulus Travma Acil Cerrahi Derg 2010; 16: 503-507.

14 Qiu J, Liu GD, Wang SX, Zhang XZ, Zhang L, Li Y et al. Analysis of injuries and treatment of 3,401 inpatients in 2008 Wenchuan earthquake - based on Chinese Trauma Databank. Chin J Traumatol 2010; 13: 297-303.

15 Butt BA, Bhatti JA, Manzoor MS, Malik KS, Shafi MS. Experience of makeshift spinal cord injury rehabilitation center established after the 2005 earthquake in Pakistan. Disaster Med Public Health Prep 2010; 4: 8-9.

16 Mallick M, Aurakzai JK, Bile KM, Ahmed N. Large-scale physical disabilities and their management in the aftermath of the 2005 earthquake in Pakistan. East Mediterr Health J 2010; 16: S98-105.

17 Chen R, Song Y, Kong Q, Zhou C, Liu L. Analysis of 78 patients with spinal injuries in the 2008 Sichuan, China, earthquake. Orthopedics 2009; 32: 322.

18 Dong ZH, Yang ZG, Chen TW, Feng YC, Wang QL, Chu ZG. Spinal injuries in the Sichuan earthquake. N Engl J Med 2009; 361: 636-637.

19 Tauqir SF, Mirza S, Gul S, Ghaffar H, Zafar A. Complications in patients with spinal cord injuries sustained in an earthquake in Northern Pakistan. J Spinal Cord Med 2007; 30: 373-377.

20 Rathore MF, Rashid P, Butt AW, Malik AA, Gill ZA, Haig AJ. Epidemiology of spinal cord injuries in the 2005 Pakistan Earthquake. Spinal Cord 2007; 45: 658-663.

$21 \mathrm{Hu} \mathrm{X,} \mathrm{Li} \mathrm{J,} \mathrm{Zhang} \mathrm{X,} \mathrm{Chen} \mathrm{S,} \mathrm{Jin} \mathrm{H,} \mathrm{Gosney} \mathrm{JE} \mathrm{et} \mathrm{al.} \mathrm{Analysis} \mathrm{of} \mathrm{functional} \mathrm{status,} \mathrm{quality}$ of life and community integration in earthquake survivors with spinal cord injury at hospital discharge and one year in the community. J Rehabil Med 2012; 44: 200-205.

22 Li Y, Reinhardt JD, Gosney JE, Zhang X, Hu X, Chen S et al. Functional outcomes of physical rehabilitation and medical complications in spinal cord injury victims of the Sichuan earthquake. J Rehabil Med 2012; 44: 206-209.

23 Rauch A, Baumberger M, Moise FG, von Elm E, Reinhardt JD. Rehabilitation needs assessment in persons with spinal cord injury following the 2010 earthquake in Haiti: a pilot study using an ICF-based tool. J Rehabil Med 2011; 43: 969-975.

24 Burns AS, O'Connell C, Landry MD. Spinal cord injury in postearthquake Haiti: lessons learned and future needs. PMR 2010; 2: 695-697.

25 EM-DAT [Internet] Available at http://www.emdat.be

26 Rathore FA, Gill ZA, Muzammil S. Letter to Editor: a comment on management of spinal injuries in the October 2005 Pakistan Earthquake. Disaster Med Public Health Prep 2011; 5: 174-175.

27 Chen J, Zhao W, Xian M, Lu J, Liang Z. Trans-province transfer of 10373 patients injured in Wenchuan Earthquake. JEBM 2009; 2: 270-276.

28 Zhang X, Reinhardt JD, Gosney JE, Li J. The NHV rehabilitation services program improves long-term physical functioning in survivors of the 2008 Sichuan earthquake: a longitudinal quasi experiment. PLoS One 2013; 8: e53995.

29 Jiang H, Dai XZ. Analysis of the rescue patterns and procedures of foreign rescue teams following the Wenchuan earthquake. JEBM 2009; 2: 122-127.

30 Burns AS, O'Connell C, Rathore F. Meeting the challenges of spinal cord injury care following sudden onset disaster: lessons learned. J Rehabil Med 2012; 44: 414-420.

31 Walk RM, Donahue TF, Stockinger Z, Knudson MM, Cubano M, Sharpe RP et al. Haitian earthquake relief: disaster response aboard the USNS comfort. Disaster Med Public Health Preparedness 2012; 6: 370-377.

32 Eitel S. Haiti Mission Report. 6 February- 7 March 2010. US Agency for International Development (USAID). Washington DC, 2010 (Unpublished).
33 Wyndaele M, Wyndaele JJ. Incidence, prevalence and epidemiology of spinal cord injury: what learns a worldwide literature survey? Spinal Cord 2006; 44: 523-529.

34 Smith E, Wasiak J, Sen A, Archer F, Burkle FM Jr. Three decades of disasters: a review of disaster-specific literature from 1977-2009. Prehosp Disaster Med 2009; 24 : 306-311.

35 Roy N, Thakkar P, Shah H. Developing-world disaster research: present evidence and future priorities. Disaster Med Public Health Prep 2011; 5: 112-116.

36 OCEBM Levels of Evidence Working Group. The Oxford 2011 Levels of Evidence. Oxford Centre for Evidence-based Medicine. Available at http://www.cebm.net/ index.aspx?o=5653

37 Brown V, Guerin PJ, Legros D, Paquet C, Pécoul B, Moren A. Research in complex humanitarian emergencies: the Médecins Sans Frontières/Epicentre experience. PLoS Med 2008; 5: e89.

38 Abramson D, Morse S, Garrett A, Redlener I. Public health disaster research: surveying the field, defining its future. Disaster Med Public Health Prep 2007; 1: 57-62.

39 King DA. The scientific impact of nations. Nature 2004; 430: 311-316.

40 Handicap International. Earthquake of 12 January 2010 - Haiti. Preliminary findings about persons with injuries - Greater Port au Prince Area: 15-26 January 2010. Available at http://www.handicap-international.us/where-we-work/programs/ haiti/haiti-earthquake-documents/

41 Paralyzed Veterans of America. Consortium for Spinal Cord Medicine. Clinical Practice Guidelines for Health Care Professionals/Consumer Guidelines. Available at http://www.pva.org/site/c.ajIRK9NJLcJ2E/b.6431479/k.3D9E/Consortium_for_Spinal_ Cord_Medicine.htm

42 Smith-Rohrberg Maru D, Andrews J, Schwarz D, Schwarz R, Acharya B, Ramaiya $\mathrm{A}$ et al. Crossing the quality chasm in resource-limited settings. Global Health 2012; 8: 41.

43 Eldar R, Marincek C. WHO/EURO Consultation on Guidelines for Physical Rehabilitation of Wounded in Disaster Situations. Ljubljana Slovenia 1996 (Unpublished). Available at http://www.worldcat.org/title/whoeuro-consultation-on-guidelines-forrehabiliation-of-physically-wounded-in-disaster-situations-19-20-february-1996/oclc/ 182919614\&referer=brief results

44 Kirshblum SC, Burns SP, Biering-Sorensen F, Donovan W, Graves DE, Jha A et al. International standards for neurological classification of spinal cord injury (Revised 2011). J Spinal Cord Med 2011; 34: 535-546.

45 DeVivo MJ, Biering-Sørensen F, New P, Chen Y. Standardization of data analysis and reporting of results from the International Spinal Cord Injury Core Data Set. Spinal Cord 2011; 49: 596-599.

46 Kirchberger I, Cieza A, Biering-Sørensen F, Baumberger M, Charlifue S, Post MW et al. ICF core sets for individuals with spinal cord injury in the early post-acute context. Spinal Cord 2010; 48: 297-304.

47 Cieza A, Kirchberger I, Biering-Sørensen F, Baumberger M, Charlifue S, Post MW et al. ICF core sets for individuals with spinal cord injury in the long-term context. Spinal Cord 2010; 48: 305-312.

48 Bryce TN, Biering-Sørensen F, Finnerup NB, Cardenas DD, Defrin R, Lundeberg T et al. International spinal cord injury pain classification: part I. Background and description. Spinal Cord 2012; 50: 413-417.

49 Bryce TN, Biering-Sørensen F, Finnerup NB, Cardenas DD, Defrin R, Ivan E et al. International Spinal Cord Injury Pain (ISCIP) Classification: Part 2. Initial validation using vignettes. Spinal Cord 2012; 50: 404-412.

50 Burkle FM, Nickerson JW, von Schreeb J, Redmond AD, McQueen KA, Norton I et al. Emergency surgery data and documentation reporting forms for sudden-onset humanitarian crises, natural disasters and the existing burden of surgical disease. Prehosp Disaster Med 2012; 27: 577-582.

51 CIRRIE Database of International Rehabilitation Research. Available at http://www. cirrie.buffalo.edu/database/index.php

52 The Cochrane Library Cochrane Evidence Aid: resources for earthquakes, Available at http://www.thecochranelibrary.com/details/collection/587779/Cochrane-Evidence-Aidresources-for-Chile-and-Haiti-earthquakes.html

53 Norwegian Satellite of the Cochrane Effective Practice and Organisation of Care Group. LMIC Databases. Available at http://www.epocoslo.cochrane.org//mic-databases

54 ReliefWebAvailable at http://www.reliefweb.int/

55 Nickerson JW, Chackungal S, Knowlton L, McQueen K, Burkle FM. Surgical care during humanitarian crises: a systematic review of published surgical caseload data from foreign medical teams. Prehosp Disaster Med 2012; 27: 1-6. 